\title{
Genital Herpes: Insights into Sexually Transmitted Infectious Disease
}

\author{
Dinesh Jaishankar ${ }^{1,2,4}$ and Deepak Shukla, ${ }^{1,2,3, *}$ \\ 1,2 Departments of Bioengineering and Ophthalmology and Visual Sciences, University of Illinois at Chicago, IL 60612. \\ ${ }^{3}$ Department of Microbiology and Immunology, University of Illinois at Chicago, IL 60612. \\ ${ }^{4}$ Department of Pathology, University of Illinois at Chicago, IL 60612. \\ * Corresponding Author: \\ Deepak Shukla, E-mail: dshukla@uic.edu
}

ABSTRACT Etiology, transmission and protection: Herpes simplex virus-2 (HSV-2) is a leading cause of sexually transmitted infections with recurring manifestations throughout the lifetime of infected hosts. Currently no effective vaccines or prophylactics exist that provide complete protection or immunity from the virus, which is endemic throughout the world. Pathology/Symptomatology: Primary and recurrent infections result in lesions and inflammation around the genital area and the latter accounts for majority of genital herpes instances. Immunocompromised patients including neonates are susceptible to additional systemic infections including debilitating consequences of nervous system inflammation. Epidemiology, incidence and prevalence: More than $\mathbf{5 0 0}$ million people are infected worldwide and most reported cases involve the age groups between 16-40 years, which coincides with an increase in sexual activity among this age group. While these numbers are an estimate, the actual numbers may be underestimated as many people are asymptomatic or do not report the symptoms. Treatment and curability: Currently prescribed medications, mostly nucleoside analogs, only reduce the symptoms caused by an active infection, but do not eliminate the virus or reduce latency. Therefore, no cure exists against genital herpes and infected patients suffer from periodic recurrences of disease symptoms for their entire lives. Molecular mechanisms of infection: The last few decades have generated many new advances in our understanding of the mechanisms that drive HSV infection. The viral entry receptors such as nectin-1 and HVEM have been identified, cytoskeletal signaling and membrane structures such as filopodia have been directly implicated in viral entry, host motor proteins and their viral ligands have been shown to facilitate capsid transport and many host and HSV proteins have been identified that help with viral replication and pathogenesis. New understanding has emerged on the role of autophagy and other innate immune mechanisms that are subverted to enhance HSV pathogenesis. This review summarizes our current understanding of HSV-2 and associated diseases and available or upcoming new treatments. doi: $10.15698 /$ mic2016.09.528

Received originally: 09.11.2015;

in revised form: 24.12.2015,

Accepted 07.01.2016,

Published 27.06.2016.

Keywords: herpes simplex virus, virus entry, viral glycoproteins, viral latency, antivirals.

Abbreviations:

3-OST-3-O-sulfotransferase,

g-glycoprotein,

HPSE - Heparanase

$H S$ - heparan sulfate

HSPG - heparan sulfate proteoglycan,

ICP-infected cell protein,

LAT - latency associated transcripts,

NMIIA - non-muscle myosin II A

PILR $\alpha$ - paired immunoglobulin-like

type 2 receptor $\alpha$;

\section{INTRODUCTION}

Genital herpes is one of the most common, persistent and highly infectious sexually transmitted viral infections mostly caused by herpes simplex virus-2 (HSV-2) and in many emerging first time cases, by HSV-1 [1]. Primary and recurrent genital herpes infections most commonly result in lesions and inflammation around the genital area. In wom- en, the sites of infection are mainly the vulva and the vagina, with some cases involving the regions of cervix and perianal. In heterosexual men infection is typically on the glans or the shaft of the penis, whereas anal infection is also reported with homosexual men. More than 500 million people are infected worldwide and most cases reported are among the age groups between $16-40$ years that 


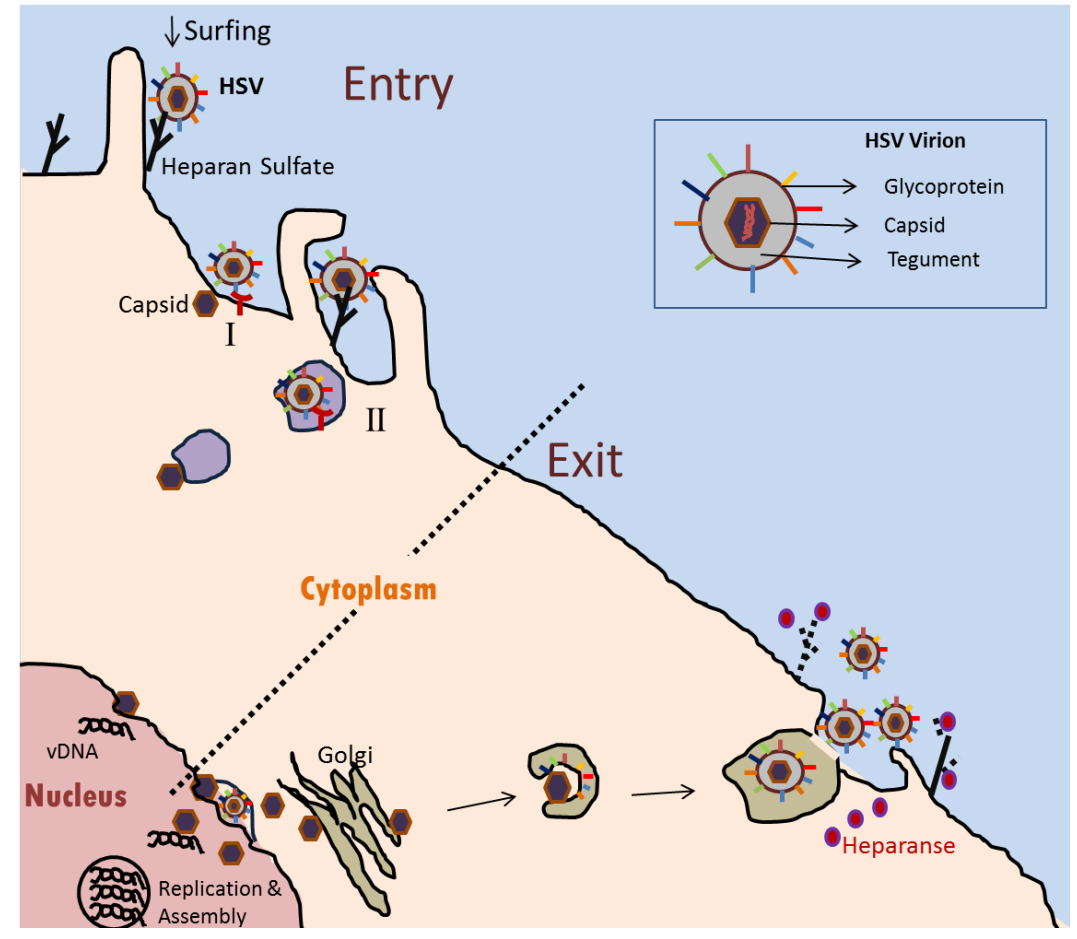

FIGURE 1: Schematic of HSV-1/HSV-2 lytic infection. The HSV-1/HSV-2 virion recognizes and attaches to the heparan sulfate proteoglycan via glycoproteins on the viral envelope. By a process called 'surfing', the virus particles can travel along filopodia-like membrane extensions to reach the surface of the cell. On the surface of the cell, viral capsid penetration can occur by fusion of envelop with the plasma membrane (I), or alternatively by endocytosis of enveloped virions with eventual fusion of the envelope with a vesicular membrane (II). In either case, gD on the virus envelope is required via its interaction with one of the receptors (shown in red): herpesvirus entry mediator (HVEM) or nectin-1 and2. In the cytoplasm, the capsid (brown) travels to the nucleus where the viral DNA is released. Multiple rounds of replication result in multiple copies of viral DNA and other components that get packaged and assembled in the nucleus. During egress, the newly assembled capsid gets its primary envelope at the peri-nuclear membrane, which is lost during egress from the outer nuclear membrane. Naked capsid travels through the cytoplasm where it receives the tegument and the viral envelope (presumably from the Golgi or the ER). Heparanase (denoted as pink spots) is an enzyme that was recently described in aiding viral egress. The enzyme cleaves of cell surface heparan sulfate (dotted black) which clears the path for the virus to exit the cell.

coincides with increased sexual activity among this age group [2]. While these numbers are an estimate, the actual numbers may be underestimated as many people are either asymptomatic or are unaware of the infection [3]. This review provides an insight into the epidemiology, pathology, our current understanding of the molecular mechanisms of infection and the currently available and upcoming treatments for genital herpes.

\section{EPIDEMIOLOGY AND PREVALENCE}

Herpesviruses are among the most ubiquitous of human infections. After infection with HSV, it is thought that the virus and the immune response to the virus persist through the life of the host. HSV infections are measured by testing various populations for the presence of antibodies specific to the virus. An estimated $90 \%$ of all people worldwide have one or both viruses $[4,5]$. HSV-1 is the more prevalent virus with $65 \%$ of persons in the United States having antibodies to HSV-1 [6], while HSV-2 infections are markedly less frequent, with $15 \%-80 \%$ of people in various populations infected [7]. HSV-1 and HSV-2 infection rates widely vary between countries. The increase in genital HSV-1 is mainly attributed to an increase in oral sex among youngsters and adults which is viewed safer than intercourse [8]. Due to this, in the USA, Canada, and other European countries, at least half of the first episodes for genital herpes have been caused by HSV-1 in the past decade [9-12]. In a study performed by the CDC it is estimated that about one in six Americans aged 14 to 49 are infected with HSV-2 and the prevalence in women was $20.9 \%$, twice as high as among men [13]. While a surge of HSV-2 seroprevalence from $16.4 \%$ to $21.8 \%$ was observed from 1976 to 1994 [14], this trend has reversed, dropping to $17.2 \%$ in 2004 [15]. In Africa and other developing countries, there is a high burden of HSV-2 infections with $>50 \%$ prevalence in the population [16]. Around $82 \%$ of women and $53 \%$ of men in the Sub-Saharan Africa are seropositive for HSV-2 [17]. HSV-2 infection rates also depend on the rates of sexual activity and are more prevalent in heavily exposed populations, such as commercial sex workers, who are nearly $100 \%$ positive, suggesting an urgent need for education and new measures for prevention [18].

\section{MOLECULAR MECHANISMS OF INFECTION}

HSV are linear, double stranded DNA viruses capable of establishing latency in humans. They belong to the family of Herpesviridae and more specifically to the sub-family of Alphaherpesvirinae. There are two sub-types: HSV-1 and HSV-2 that are closely related but differ slightly in tissue tropism and antigenic properties. The viral DNA is present in the core that is enclosed in a protein shell called the capsid (Fig. 1). The icosahedral shaped capsid is $\sim 125 \mathrm{~nm}$ in diameter, which is connected to and surrounded by a glycoprotein expressing lipid bilayer membrane envelope via a protein coat called the tegument. The viral envelope contains at least 12 glycoproteins many of which play major roles in the entry and egress of the virus. A list of HSV glycoproteins along with their reported functions is provided in Table 1. 
TABLE 1. List of HSV glycoproteins and their reported functions.

\begin{tabular}{c|c|c}
\hline Glycoprotein & Function & References \\
\hline gB & Fusogenic protein: class III & {$[23]$} \\
\hline gC & Attachment and C3b receptor & {$[20,24]$} \\
\hline gD & Virus entry and fusion & {$[21]$} \\
\hline gE & Virus spread and Fc receptor & {$[19,21]$} \\
\hline gH & Virus entry and fusion & {$[22,26,27]$} \\
\hline gl & Virus spread and Fc receptor & {$[28,29]$} \\
\hline gK & Virus spread and egress & {$[19,24]$} \\
\hline gL & Viral entry and fusion & {$[30-32]$} \\
\hline $\mathrm{gM}$ & Virus assembly and fusion & \\
\hline
\end{tabular}

The lifecycle of HSV has been mostly studied and characterized using HSV-1 infections. However, HSV-2 infections are considered similar to HSV-1 infections. Different stages in the HSV lifecycle can be broadly classified into:

i. Attachment: Initiation of infection begins with the attachment of viral glycoproteins to the cell surface. Heparan sulfate proteoglycans (HSPGs) on the cells serve as attachment sites for HSV [19]. Glycoproteins B and C (gB and gC) on the HSV envelop bind to the HSPGs and are essential to initiate attachment. A study by Herold et al., using a gB and gC null virus showed reduction in the overall virus attachment to the cells as well as reduction in virus infectivity [20]. Moreover, it has been shown that in the absence of gC gB can take over and help in attachment to cells, indicating a gC-independent mode of viral attachment [33]. HSV was shown to bind to HS (heparan sulfate) on the filopodia, which are plasma membrane protrusions, and use filopodial interaction to migrate towards the cell body to initiate entry. This process was termed "viral surfing" [34]. In this study, viral particles were shown to surf along the filopodia and the formation of filopodial structures increased upon HSV infection, possibly due to activation of Rho GTPase signaling during virus attachment to cells. Fluorescence imaging revealed that HSPG expression is higher along the filopodial structures. This mode of attachment has also been reported for vaccinia virus, human papilloma virus type 16 , hepatitis $C$ virus, and human immunodeficiency virus (HIV) [35].

ii. Entry: After the initial attachment to the cell surface, virus entry is the next step in the lifecycle. Various modes of viral entry have been established. The virus is taken into the cells by either direct fusion with the plasma membrane, which is independent of $\mathrm{pH}$ change, or through endocytosis mediated by specific cellular receptors. The glycoprotein D (gD) on HSV plays an important role in both of the aforementioned uptake processes and glycoproteins $\mathrm{H}$ and $\mathrm{L}(\mathrm{gH}$ and $\mathrm{gL}$ ) act in concert to complete the fusion machinery. To date the following receptors have been identified for gD: herpes virus entry mediator (HVEM), nectin-1 and -2 and 3O sulfated heparan sulfate (3-OS HS) [21]. HVEM was the first identified HSV receptor that belongs to the tumor necrosis factor (TNF) superfamily. The next set of receptors identified is represented by nectin- 1 and -2 . They belong to the immunoglobulin superfamily. The last receptor is a rare modification of the large sugar molecule HS mediated by the 3-O-sulfotransferase 3 (3-OST-3). 3-OST-3 belongs to the family of 3-O sulfotransferases (3-OSTs) that place sulfate groups at the $3-\mathrm{OH}$ position on the glucosamine in $\mathrm{HS}$. This specific and rare modification of HS dictates the biological activity of HS and occurs during the last step of HS biosynthesis. As an example, modification of HS by 3-OST-1 serves as a binding site for antithrombin, a major player in anticoagulation [36]. 3-OST-3 modified HS serves as an entry receptor for HSV and addition of soluble form of 3-OS HS in HSV resistant cell lines showed increased viral entry [38, 39]. Interestingly, 3-OST-3 generated receptor fails to mediate HSV-2 entry but may probably help in the attachment of HSV-2 [19, 38].

Viral entry can occur in the presence of any one of the aforementioned receptors and absence of all three receptors abolishes viral entry. Even though gD is needed for receptor-mediated endocytosis and also for the direct fusion of viral envelop to the plasma membrane, there seems to be no clear consensus on how and which mode of entry the viruses use in human hosts or animal models. While entry into some cultured cells like $\mathrm{CHO}$, HeLa and HCEs are reported to be through receptor mediated endocytosis, entry into Vero and neuronal cell lines are through direct fusion with the plasma membrane $[39,40]$. In addition to gD playing a vital role in viral entry, accumulating evidence also suggests the important role of gB in HSV entry as a gB null virus was unable to enter and cause infection in target cells [41]. Paired immunoglobulin-like type 2 receptor a (PILR $\alpha$ ) has been shown to associate with gB to function as a co-receptor in aiding HSV-1 entry. Mutations on the sites where gB attaches to PILR $\alpha$ not only reduced viral entry but also reduced viral replication and neuroinvasiveness [42-44]. Furthermore, another protein that belongs to the sialic acid-binding Ig-like lectin family which shares a similar homology to PILR $\alpha$ called the myelin-associated glycoprotein (MAG) acts as a co-receptor for HSV-1 entry when expressed exogenously [45]. Another co-receptor called non-muscle myosin IIA (NMIIA) was also identified to bind gB on the cell surface and aide in the viral entry [46]. As an actin binding motor protein, NM-IIA plays a critical role in cell adhesion and migration. The glycoproteins $\mathrm{gH}$ and $\mathrm{gL}$ together with gB and gD form the fusion complex [47, 48]. $\mathrm{gH}$ exists as a hetero-oligomeric complex with $\mathrm{gL}$. This 
complex is essential for the processing and cell surface expression of $\mathrm{gH}[49,50]$ and is conserved in many of the herpesviruses [51]. Apart from playing a role in the fusion machinery, the $\mathrm{gH} / \mathrm{gL}$ complex plays a role in virus entry by interacting with various cell surface proteins [52], integrins being the most common. Interaction of $\mathrm{gH}$ with integrin $\alpha v \beta 3$ facilitates HSV-2 viral entry and calcium signaling in human genital tract epithelial cells [53]. Another study shows that $\alpha v \beta 6$ and $\alpha v \beta 8$ serve as interchangeable receptors for $\mathrm{gH} / \mathrm{gL}$ that promote endocytosis and activation of membrane fusion [54]. A recent study by the same group also found that conformational changes in the above mentioned integrin receptors are essential to promote the dissociation of $\mathrm{gL}$ from the $\mathrm{gH} / \mathrm{gL}$ complex, a proposed new mechanism in HSV viral entry [55].

Other alternative modes of viral entry have also been identified. A phagocytosis-like uptake of the virus particles was reported to be observed once the virus particles have attached to the filopodia; it is believed to exhibit mixed traits of endocytosis and phagocytosis [56]. Cytoskeleton rearrangement and their associated cellular signaling pathways have also been implicated in facilitating HSV entry into cells [57]. Rho-GTPase signaling pathway involving Rho-A and cdc42, key modulators in the formation of filopodia, were shown to be activated and aide in the phagocytic-like uptake of the virus [56]. Another signaling pathway called phosphoinositide 3 kinase (PI3K) pathway, which is involved in the downstream of the filopodial formation, was also found to affect multiple steps in the HSV entry [58]. This same pathway is also implicated to control the activity of cofilin, a family of actin-binding proteins, in facilitating entry of virus into neuronal cells [59]. The activation of Akt signaling in triggering calcium release which aids in HSV viral entry has also been shown [60].

iii. Capsid Transport and Replication: Upon successful entry into cells, the viral capsid and tegument proteins are released into the cytoplasm. The virion host shutoff protein (vhs) is a viral tegument protein that is released into the cytoplasm after entry and degrades host mRNAs that regulate stress response. The capsid then translocates to the nucleus along microtubules via the dynein and dynactin motor proteins and releases the viral DNA into the nucleoplasm [61-63]. A recent study reported the role of heatshock protein 90 (Hsp90) to be involved with HSV capsid transport to the nucleus via interaction with acetylated $\alpha$ tubulin [64]. The uncoating of viral DNA occurs at the nuclear pore.

iv. Replication and Assembly: Once inside the nucleus, several viral genes are expressed in an ordered fashion. The proteins of the $\alpha$ genes or intermediate early (IE) genes are the first to be transcribed. The products of these genes are termed as infected cell protein (ICP) and there are five ICPs: 0, 4, 22, 27 and 47 . The virus encodes a tegument protein: VP16 that aids in the transcription of the $\alpha$ genes. The expression of ICP4 is then thought to drive the expression of the $\beta$ genes or the early genes. The $\beta$ genes encode for various proteins that promote viral DNA replication, including the enzyme thymidine kinase (TK). The virus utilizes TK for replication leading to the expression of the $\psi$ or late genes. The proteins of the $\gamma$ genes encode for several components of the viral structure including capsid and envelop proteins. Various viral components are formed which then assemble and the viral DNA is repackaged into a new capsid. Fully assembled capsid exits from the nucleus by acquiring a glycoprotein-containing envelop at the inner nuclear membrane and losing it at the outer membrane when the naked capsid is released in the cytoplasm for re-envelopment using a Golgi-derived membrane (Fig. 1).

v. Autophagy Modulation during Active Replication: The role of autophagy, a cellular process involved in maintaining the metabolic and homeostatic activity, in HSV replication has been widely studied. The ICP34.5 protein, a neurovirulence factor, regulates the replication of HSV by controlling the autophagic pathway via inhibition of either PKR/elF2a signaling pathway $[65,66]$ or beclin- 1 , a protein involved in the formation of autophagosomes [67]. A recent study showed that a basal level of autophagy is needed for efficient replication of virus and disrupting the basal level would lead to reduced viral titers [68]. Another recent study showed the role of a host cytoplasmic protein called axin in controlling autophagy and HSV replication [69]. The results from this study indicate that axin expression reduces the levels of cellular autophagy induced by HSV, resulting in enhanced HSV replication.

vi. Latency and Reactivation: One of the key traits of this family of viruses is to go latent for the life of the host after primary infection. How and why the virus goes latent is only partially understood and is one of the hot topics in herpes research. After a lytic infection the virus has the ability to evade and mask itself from the host defense. Latency is established when the virus migrates to the sensory ganglia via a retrograde fashion and invades the nucleus of the neurons (Fig. 2). In the nucleus the HSV genome is maintained in a circular form and remains in a silent state. During this state, a region of the genome that encodes for the latency associated transcripts (LATs) remains active [70]. Kramer et al. also showed the presence of HSV transcripts using RT-PCR analyses in latently infected mouse ganglia $[71,72]$. The exact role and function of the LATs also remains to be completely understood. However, research over the last decade has revealed the common functions of LAT: they help in reducing the expression of the viral genome thereby maintaining them in a latent state protected from the immune system [73] and they protect infected neurons from apoptosis, thus increasing the amount of latent transcripts that would eventually increase the viral load upon reactivation [74, 75]. In addition, the host immune system has also been implicated to play a vital role in viral latency. Studies in the mouse models of latent HSV infection revealed the presence of infiltrating immune cells and cytokines in latently infected ganglia [76-78] while some suggest that the presence of low viral transcript levels could lead to a local milieu of immune effectors that could repress HSV gene expression [79, 80]. Some evidence also suggests the role of neuronal functio in maintaining latency [81-83]. Furthermore, during latent infection, the ability of some parts of the HSV genome to 


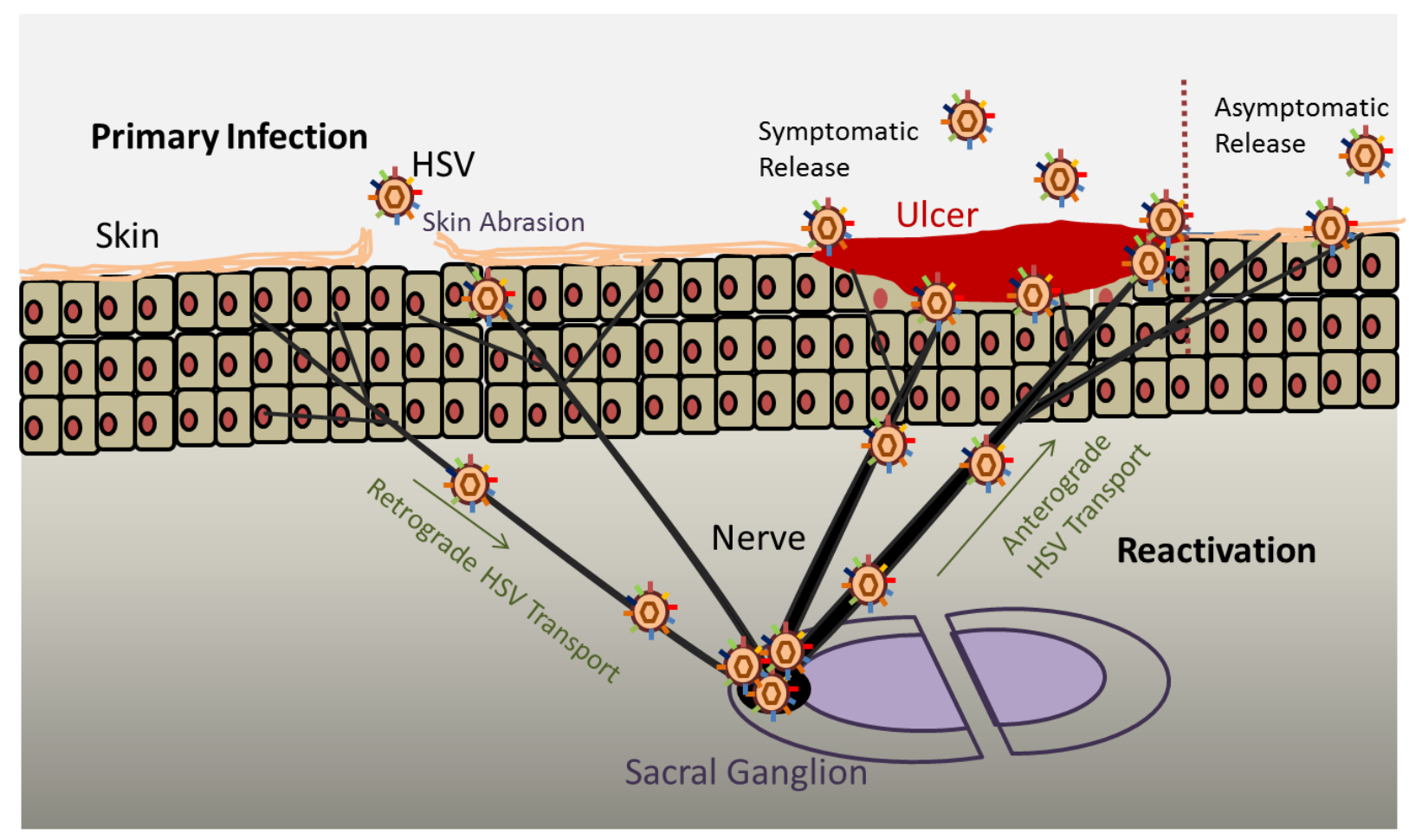

Figure 2: Schematic of Primary Infection and Reactivation. Primary infection occurs when a host is exposed to the virus for the first time. When a person is exposed to HSV, the virus infects the epithelial cells. Depending on the immune system of the host, lytic infection leads to virus shedding that can cause symptoms such as ulcers or remain asymptomatic. After lytic infection, the virions reach the nerve endings and through a retrograde transport, reach the sacral ganglion where it establishes latency till the life of the host. Recurrent infections occur when the virus gets reactivated due to stress, environmental conditions and other unknown factors. Reactivation causes the virus from the sacral ganglion to travel to the site of primary infection or high nerve endings via an anterograde fashion where virus shedding can cause symptoms or remain asymptomatic depending on the host immune system.

remain transcriptionally active and inactive suggested the presence of epigenetic control. Two studies that used computational analysis and latently infected mice revealed that DNA methylation, a most common epigenetic mechanism, did not regulate HSV latent gene expression [84, 85], leading to the investigation of other epigenetic mechanisms.

The role of chromatin and HSV latency has gained increasing popularity as the HSV DNA is devoid of histones [86] but upon infection gets assembled into the nucleosome [87] and associates with histones [88]. However whether heterochromatin or euchromatin play a role in HSV latency was not known. Only recently, using various molecular techniques, the presence of heterochromatin or euchromatin in HSV-infected cells has been studied to provide a basis for a chromatin-based epigenetic mechanism of HSV gene regulation in different cell types [89]. In a study by Kubat et al., their findings showed that active chromatin was associated with LAT gene as increasing levels of acetylated H3 histone were found to be associated with the LAT promoter and enhancer compared with the ICPO gene [90]. In another study by Wang et al., it was shown that as latent infection is established the HSV lytic genes are progressively associated with chromatin that contains dimethylation of $\mathrm{H} 3 \mathrm{~K} 9 \mathrm{me} 2$, which is an indicator of heterochromatin [91]. Thus there is a general notion that during latent infection the LAT gene is associated with euchromatin whereas the lytic genes are associated with heterochromatin. The study by Amelio et al. gave insights into how and why different chromatin are maintained and regulated separately on the latent viral genome [92]. Their study identified candidate insulator elements, DNA sequences that bind protein factors that maintain chromatin boundaries. These contain CCCTC sites that are bound by the CCCTC-binding factor (CTCF) upstream of the LAT promoter boundary and in the LAT intron. They proposed that insulators keep the LAT euchromatin activity within a boundary and heterochromatin outside of the same boundary.

Reactivation of the latent virus occurs when an external stimuli or 'stress' is applied to the neuron. Various factors such as environmental conditions, fever, exposure to sunlight and other unknown conditions have been attributed to cause reactivation but their exact targets at the molecular level remain unknown. When the virus reactivates it travels from the sensory ganglia via anti-retrograde fashion to the primary infection site or sites of high neuron innervations where active virus replication and shedding occur and symptoms like pain, inflammation and lesions develop. In an effort to understand the exact role of LATs in the 
reactivation of HSV, LAT encoded micro RNAs (miRNA) were discovered. miRNAs are a family of non-coding RNA that is approximately 22 nucleotides in length. They usually function at a post-transcription level by inhibiting protein synthesis via mRNA degradation. HSV miRNAs have been shown to be expressed during productive infection, which helps degrade host immune responses as well as during latency, which helps in establishing latency or helps in reactivation [93].

vii. Egress: Upon formation of capsid and packaging of the virus DNA, the virions eventually have to egress or leave the nucleus and the cell to get into the extracellular environment. While the process of HSV egress still requires some clarity due to varying experimental models and complexity in studying the virus-nuclear interactions, the following is the accepted model for viral egress. Budding is the initial step in the nuclear egress of HSV. In this process the capsid acquires the envelope from the inner nuclear membrane and two viral proteins: UL31 and UL34 are reported to be necessary for the budding process [94]. Once the virus reaches the perinuclear region, it is thought to lose the primary envelope or undergoes de-envelopment and evidence suggests that the final assembly of tegument, envelope and the glycoproteins occur within the cytoplasmic compartments (presumably in the Golgi or Endoplasmic Reticulum, ER). During productive infection either in primary infection or after reactivation, for efficient transmission and infection, the virus needs to spread to neighboring cells. The release of the virus from infected cells requires both host factors and viral components. Among the viral components, glycoproteins $\mathrm{E}$ and I (gE and gI) are needed for efficient spread of viruses in certain polarized and non-polarized epithelial cells and neuronal cells [95, 22]. Among the host factors, a HS degrading enzyme: heparanase (HPSE) has been recently shown to aide in viral egress [96]. The study shows how the levels of HPSE increase over time with HSV infection as active form of HPSE is translocated to the plasma membrane of infected cells to remove HS for smoother release of newly generated virions. The role of myosin motor proteins such as NMIIA and myoVa have also been implicated in HSV egress $[97,98]$.

\section{SYMPTOMS AND PATHOLOGY}

Genital herpes is predominantly transmitted through sexual contact. Viral transmission by oro-genital contact is mostly HSV-1 and therefore the number of genital HSV-1 cases is on the rise [99-101]. Virus shedding is more predominant in sites like mouth and mucosal surfaces such as the vagina. Contact with any one of these increases the risk of being infected with HSV.

An episode or outbreak is termed as the phase in which individuals experience symptoms and the severity of these episodes depends on previous immunity to HSV. Notably, almost $25 \%$ of people presenting with a first clinical episode of genital herpes have serological evidence of past HSV-2 infection at the time of presentation, suggesting initial infection was asymptomatic [102]. In many other instances of primary infections where the patient encoun- ters HSV for the first time the first episode may occur anywhere between 2 days to 2 weeks after primary infection. Primary infections are clinically most severe and most likely symptomatic [103]. Symptoms like fever, itching and muscle pains usually in the lower part of the body are most common in primary infection; $40 \%$ of men and $70 \%$ of women also report fever, headache, malaise, and myalgias [104]. Papule formulation followed by a wide distribution of blisters or lesions appear around the genital areas that eventually break to form ulcers (Fig. 2). Over a period of time the ulcers crust and heal. In women common sites for lesion are the cervix, vagina, labia majora and minora and perianal region through infected vaginal fluid and in men it is mostly on the shaft or the glans of the penis. Anal lesions are also reported in homosexual men. Primary infections either by HSV-1 or by HSV-2 cannot be differentiated just by clinical symptoms; additional laboratory testing is needed to differentiate between the two viruses.

At the tissue and molecular level, HSV-2 infects the epithelial cells on the genital mucosa leading to an increase in inflammatory response and cell death at the site of infection. Multinucleated cells and syncytia formation are the most common observation in cells infected with HSV. The recruitment of macrophages, natural killer cells, B-cell and T-cell mediated immunity $[105,106]$ and the release of cytokines has been reported to play a role in innate and adaptive immunity to HSV infections. This contributes to a chronic inflammatory state in genital skin and mucosa. Histopathologic studies of foreskin in HIV-seronegative men after adult circumcision have shown a higher concentration of $\mathrm{CD}^{+}$and $\mathrm{CD}^{+}$T-cells in HSV-2-seropositive compared with HSV-2-seronegative men [107]. During the course of primary infection, the virus spreads via a retrograde fashion along the microtubules lining the axons to the dorsal root ganglia (DRG) where the neuronal cells act as reservoirs for the virus to remain latent [108]. Upon reactivation due to factors such as stress and other unknown conditions, the virus spreads from the DRG to the epithelial cells via an anterograde fashion where a lytic replication of the virus follows, resulting in virus shedding. This is the cause of recurrent infections and these infections are usually asymptomatic or may be associated with a classic genital ulcer. While the innate immune system, specifically the $\mathrm{CD}^{+} \mathrm{T}$-cells and the plasmacytoid dendritic cells, are attributed in controlling latency and reactivation of the virus $[80,109,110]$, recent reports suggest otherwise. Studies have shown that $\operatorname{CD} 8 \alpha$ dendritic cells help drive the establishment of HSV-1 latency [111, 112]. At a clinical and subclinical level, the severity of viral reactivation varies widely from person to person and depends on cell mediated immunity that is considered important for control of viral replication $[113,114]$

\section{DIAGNOSIS}

Diagnosis of genital herpes based purely on clinical presentation is often not accurate and could be misleading. Symptoms occurring from other bacterial infections like Treponema pallidum or Haemphilus ducreyi could be confused 
with HSV resulting in wrong diagnosis [115]. Genital herpes may also cause atypical symptoms that occur at unusual sites such as the thighs or the buttocks. HSV-2 is also found to be a co-factor for HIV-1, which is one of the leading causes of sexually transmitted infections and at times it becomes difficult to diagnose the symptoms that occur due to HIV-1 co-infections [116]. Hence, along with clinical diagnosis, laboratory tests are required to accurately diagnose genital herpes. To determine the presence of HSV in laboratory, swabs from the genital lesions are taken and tested by the following common techniques:

i. Viral culture of HSV has been a gold standard for laboratory diagnosis of HSV for the past two decades. Using the swabs from the genital lesions, the virus can be grown on tissue culture, usually within 5 days, that is then detected using immunofluorescence assays or by enzyme immunoassay. The limitation with this method is that it lacks sensitivity as more viruses are usually obtained from patients with primary infection $(80 \%)$ but less from patients with recurrent infections $(20-50 \%)$ or patients whose lesions have begun to heal [117].

ii. Polymerase Chain Reaction (PCR): This method of nucleic acid amplification has emerged as the next common method to assess the presence of HSV. Determining HSV by PCR is faster and four times more sensitive compared to viral culture $[118,119]$. Based on this method, three assays have been approved by the US Food and Drug Association for the detection of HSV in genital lesions. These include IsoAmp HSV Assay, BioHelix Corporation; MultiCode-RTx Herpes Simplex Virus 1 \& 2 Kit, EraGen Biosciences, Inc. and BD ProbeTec Herpes Simplex Viruses (HSV I \& 2) QX Amplified DNA Assays, BD Diagnostic Systems. With increasing technology and advances in kit developments for HSV detection and typing using PCR, this method is rapidly replacing the viral culture assay.

iii. Serotyping: This method can not only be used to detect the presence of HSV but can also be used to differentiate between genital herpes originating from HSV1 or HSV-2. Type-specific IgG against the glycoprotein G (gG) of HSV-1 and HSV-2 are available that can be used to distinguish between the two viruses [120]. Serotyping has another advantage in that it detects the presence of HSV to confirm if the infection is a primary or recurrent infection. In primary infection, type-specific HSV antibodies can take from 2 weeks to 3 months to develop. Therefore, an initial absence of IgG antibodies specific for gG and subsequent development of such antibodies after 12 weeks confirms new HSV infection. Clinicians also recommend this method to diagnose genital herpes when there are no lesions or the above mentioned detection tests do not provide substantial results.

While this review only mentions the above common techniques to diagnose genital herpes in a laboratory setting, there are currently other methods and techniques being developed by research institutes and companies. For example, LeGoff et al. provide a detailed description of other available and upcoming diagnostic methods [121].

\section{TREATMENT AND PREVENTION}

Genital herpes conditions are primarily treated with antivirals that aim at controlling viral replication. Acyclovir, its analogue Valacyclovir and Famcyclovir (prodrug of Pencyclovir) are currently prescribed for genital herpes treatment. These drugs are nucleoside analogues that specifically inhibit the herpesvirus DNA polymerase. While cyclovir is available in oral and intravenous formulations, Valacyclovir and Famcyclovir are available only as oral formulations. For primary infections where the symptoms can be severe, antiviral therapy is usually started even before the symptoms are confirmed by laboratory diagnosis and the duration of the therapy is 7-10 days or till the lesions are healed [122]. In severe cases, to relieve pain, clinicians recommend the use of analgesics or sitz baths where the patients' hips and buttocks are immersed in lukewarm water [117].

Preventive strategies to efficiently reduce the transmission of the virus also exist and in combination with the above mentioned treatments there could probably be a significant reduction of viral transmission. In the case of people that have symptomatic viral shedding, the most common preventive strategy is to abstain from sexual activity or to use condoms. A prospective study showed significantly lowered levels of viral acquisition among partners that used male condoms [123]. Although it is thought that female condoms can also reduce virus transmission, this has not been clinically investigated. Applications of topical microbicides to prevent genital herpes infections are also being investigated. This strategy involves the use of natural or synthetic products that either increase the natural vaginal defenses or inactivate the HSV virions [124, 125]. A recent study showed that vaginal application of tenofovir gel, an antiviral microbicide which functions as a nucleotide reverse-transcriptase inhibitor, reduced the levels of HSV-2 acquisition among women in South Africa [5].

Various other therapeutic and prevention strategies that target different stages of virus lifecycle are currently being investigated. Peptide therapeutics is fast rising owing to the ease of synthesis, modifications and their high specificity [126]. They are being synthesized and used as inhibitors against HSV infections [127]. The TAT (transactivator of transcription)-peptide, derived from HIV, has been shown to inhibit infection of HSV in the in vitro and in vivo models of HSV infections [128, 129]. A study showed the effect of a synthetic 3-OS HS specific peptide: G2 in blocking HSV-2 infections in human cervical (HeLa) cell lines. This peptide significantly blocked the entry and thereby the spread of the virus [130] and a D-enantiomer of this peptide exhibits higher stability and more promise in inhibiting HSV infection [131]. Another study designed synthetic peptides specific to the glycoproteins gD and gG and showed that these peptides can effectively recognize HSV-2 antibodies and hence may be used for serodiagnostic assays [132]. Because HSV utilizes the cytoskeleton filaments and kinases during its entry, a recent study showed that blocking the myosin light chain kinase (MLCK) with inhibitors 
such as blebbistatin significantly reduces HSV infection [133], providing new evidence for potential targets in blocking HSV infections. The advent of nanoparticles in drug delivery was successful, owing to their ability to provide sustained or extended delivery of drugs at a local site. Nanoparticles or nanoparticle compositions to protect against HSV-2 infections are also being actively researched. Zinc Oxide $(\mathrm{ZnO})$ nanoparticles exhibited significant antiviral activity in both the in vitro model using vaginal epithelial cells and the in vivo mice model of HSV-2 infections [134]. Three different modes of treatment were used in this study: prophylaxis, therapeutic and neutralization. In all the three modes of treatment, the $\mathrm{ZnO}$ nanoparticles showed promising results in blocking HSV-2 infections. Another study showed the potential antiviral use of mucuspenetrating nanoparticles [135]. In this study, acyclovir monophosphate loaded mucus-penetrating nanoparticles showed an increase in drug retention and distribution thereby providing an effective protection against HSV-2 challenge.

Protection against genital herpes infections can be enhanced by induction of protective immune responses using vaccines. Vaccines against genital herpes are underway and in the majority of clinical trials only prophylactic vaccines have seen success so far. There have been no reports of any therapeutic vaccines that show promise against genital herpes infections. These vaccines consist of subunits of glycoproteins such as gD or gB. A gD2 subunit vaccine, when administered with alum as adjuvant, showed around $39-46 \%$ efficacy in preventing HSV-2 infections in patients that were seronegative for HSV-1 and HSV-2 but did not provide protection to patients that were seropositive for HSV-1 [136, 137]. Other viral glycoproteins such as gC and gE are also being used as vaccines to study their effectivity in blocking genital herpes infections [138, 139]. Peptide based vaccines are also being developed to incite immune responses against HSV-2 infections. A study developed a peptide based vaccine: HerpV, which generates $\mathrm{CD}^{+}$and $\mathrm{CD}^{+}$responses when subjected to HSV-2 challenge $[140,141]$.

\section{REFERENCES}

1. Wald A (2006). Genital HSV - 1 infections. Sex Transm Infect 82(3): 189-190.

2. Felman YM and Nikitas JA (1983). Sexually transmitted diseases and child sexual abuse. Part II. N Y State J Med 83(5): 714-716.

3. Kinghorn GR (1993). Genital herpes: natural history and treatment of acute episodes. J Med Virol Suppl 1: 33-38.

4. Abdool Karim SS, Abdool Karim Q, Kharsany ABM, Baxter C, Grobler AC, Werner L, Kashuba A, Mansoor LE, Samsunder N, Mindel A, and Gengiah TN (2015). Tenofovir Gel for the Prevention of Herpes Simplex Virus Type 2 Infection. N Engl J Med 373(6): 530-539.

\section{CONCLUSION AND FUTURE DIRECTIONS}

There is no doubt that our understanding of HSV-2 lifecycle and associated pathogenesis has improved dramatically over the last several years but challenges remain in many areas, especially those relating to disease management and prevention. The new knowledge has provided a major opportunity to develop new strategies for patient care by combining our understanding of viral infection mechanisms, host immune responses, and the viral mechanisms that subvert them. New anti-HSV drugs are on the horizon, many of which may target other herpesviruses as well. At present, the development of vaccines against HSV-2 is a highly active area of research and many innovative strategies are currently being tested for an effective vaccine generation. Future clinical trials will see many new, non-nucleoside anti-herpetic drug candidates as well as many newer approaches, including immune-based therapeutics. An area that needs extra attention is rapid diagnostics, especially since genital herpes can be caused by both HSV-1 and HSV-2. Therefore quick and easily available tests can yield much better results in reducing symptoms and lowering transmission rate. Any success in reducing transmission rate will mean a step closer to the greatest challenge for herpes virologists, which is complete elimination of this lifelong infection.

\section{ACKNOWLEDGMENTS}

This work is supported by a NIH grant (AI103754) to D.S.

\section{CONFLICT OF INTEREST}

The authors declare no conflict of interest.

\section{COPYRIGHT}

(C) 2016 Jaishankar and Shukla. This is an open-access article released under the terms of the Creative Commons Attribution (CC BY) license, which allows the unrestricted use, distribution, and reproduction in any medium, provided the original author and source are acknowledged.

Please cite this article as: Dinesh Jaishankar and Deepak Shukla (2016). Genital Herpes: Insights on a Sexually Transmitted Infectious Disease. Microbial Cell 3(9): 438-450.

5. Wald A and Corey L (2007). Persistence in the population: epidemiology, transmission. In: Arvin A, Campadelli-Fiume G, Mocarski E, Moore PS, Roizman B, Whitley R, Yamanishi K, editors. Human Herpesviruses: Biology, Therapy, and Immunoprophylaxis. Cambridge University Press, Cambridge. http://www.ncbi.nlm.nih.gov/books/NBK47447/.

6. Xu F, Schillinger JA, Sternberg MR, Johnson RE, Lee FK, Nahmias AJ, and Markowitz LE (2002). Seroprevalence and Coinfection with Herpes Simplex Virus Type 1 and Type 2 in the United States, 1988-1994. J Infect Dis 185(8): 1019-1024.

7. Huengsberg M (2000). Sexually Transmitted Diseases. Sex Transm Infect 76(6): 498-498. 
8. Halpern-Felsher BL, Cornell JL, Kropp RY, and Tschann JM (2005). Oral versus vaginal sex among adolescents: perceptions, attitudes, and behavior. Pediatrics 115(4): 845-851.

9. Roberts CM, Pfister JR, and Spear SJ (2003). Increasing proportion of herpes simplex virus type 1 as a cause of genital herpes infection in college students. Sex Transm Dis 30(10): 797-800.

10. Scoular A, Norrie J, Gillespie G, Mir N, and Carman WF (2002). Longitudinal study of genital infection by herpes simplex virus type 1 in western Scotland over 15 years. BMJ 324(7350): 1366-1367.

11. Manavi K, McMillan A, and Ogilvie M (2004). Herpes simplex virus type 1 remains the principal cause of initial anogenital herpes in Edinburgh, Scotland. Sex Transm Dis 31(5): 322-324.

12. Buxbaum S, Geers M, Gross G, Schofer H, Rabenau HF, and Doerr HW (2003). Epidemiology of herpes simplex virus types 1 and 2 in Germany: what has changed? Med Microbiol Immunol (Berl) 192(3): 177-181.

13. Morbidity and Mortality Weekly Report: MMWR (2010). U.S. Department of Health, Education, and Welfare, Public Health Service, Center for Disease Control. http://www.cdc.gov/mmwr/preview/mmwrhtml/mm5915a3.htm.

14. Malkin J-E (2004). Epidemiology of genital herpes simplex virus infection in developed countries. Herpes J IHMF 11 Suppl 1: 2A - 23A.

15. Xu F, Sternberg MR, Kottiri BJ, McQuillan GM, Lee FK, Nahmias AJ, Berman SM, and Markowitz LE (2006). Trends in herpes simplex virus type 1 and type 2 seroprevalence in the United States. JAMA 296(8): 964-973.

16. Weiss HA, Buve A, Robinson NJ, Van Dyck E, Kahindo M, Anagonou $S$, Musonda R, Zekeng L, Morison L, Carael M, Laga M, and Hayes RJ (2001). The epidemiology of HSV-2 infection and its association with HIV infection in four urban African populations. AIDS Lond Engl 15 Suppl 4: S97-S108.

17. Weiss $H$ (2004). Epidemiology of herpes simplex virus type 2 infection in the developing world. Herpes J IHMF 11 Suppl 1: 24A - 35A

18. Watson-Jones D, Weiss HA, Rusizoka M, Baisley K, Mugeye K, Changalucha J, Everett D, Balira R, Knight L, Ross D, and Hayes RJ (2007). Risk factors for herpes simplex virus type 2 and HIV among women at high risk in northwestern Tanzania: preparing for an HSV-2 intervention trial. J Acquir Immune Defic Syndr 46(5): 631-642.

19. Shukla D and Spear PG (2001). Herpesviruses and heparan sulfate: an intimate relationship in aid of viral entry. J Clin Invest 108(4): 503510.

20. Herold BC, WuDunn D, Soltys N, and Spear PG (1991). Glycoprotein $C$ of herpes simplex virus type 1 plays a principal role in the adsorption of virus to cells and in infectivity. J Virol 65(3): 1090-1098.

21. Spear PG, Eisenberg RJ, and Cohen GH (2000). Three classes of cell surface receptors for alphaherpesvirus entry. Virology 275(1): 1-8.

22. Dingwell KS and Johnson DC (1998). The Herpes Simplex Virus gEgl Complex Facilitates Cell-to-Cell Spread and Binds to Components of Cell Junctions. J Virol 72(11): 8933-8942.

23. Weissenhorn W, Hinz A, and Gaudin Y (2007). Virus membrane fusion. Membr Traffick 581(11): 2150-2155.

24. Friedman HM, Cohen GH, Eisenberg RJ, Seidel CA, and Cines DB (1984). Glycoprotein $C$ of herpes simplex virus 1 acts as a receptor for the C3b complement component on infected cells. Nature 309(5969): 633-635.

25. Baucke RB and Spear PG (1979). Membrane proteins specified by herpes simplex viruses. V. Identification of an Fc-binding glycoprotein. J Virol 32(3): 779-789.
26. Johnson DC and Feenstra V (1987). Identification of a novel herpes simplex virus type 1-induced glycoprotein which complexes with gE and binds immunoglobulin. J Virol 61(7): 2208-2216.

27. Johnson DC, Frame MC, Ligas MW, Cross AM, and Stow ND (1988) Herpes simplex virus immunoglobulin G Fc receptor activity depends on a complex of two viral glycoproteins, gE and gl. J Virol 62(4): 13471354

28. David AT, Baghian A, Foster TP, Chouljenko VN, and Kousoulas KG (2008). The herpes simplex virus type 1 (HSV-1) glycoprotein $\mathrm{K}(\mathrm{gK})$ is essential for viral corneal spread and neuroinvasiveness. Curr Eye Res 33(5): 455-467.

29. Hutchinson $L$ and Johnson DC (1995). Herpes simplex virus glycoprotein K promotes egress of virus particles. J Virol 69(9): 5401-5413.

30. Kim I-J, Chouljenko VN, Walker JD, and Kousoulas KG (2013). Herpes simplex virus 1 glycoprotein $M$ and the membrane-associated protein UL11 are required for virus-induced cell fusion and efficient virus entry. J Virol 87(14): 8029-8037.

31. Baines JD, Wills E, Jacob RJ, Pennington J, and Roizman B (2007) Glycoprotein M of Herpes Simplex Virus 1 Is Incorporated into Virions during Budding at the Inner Nuclear Membrane. J Virol 81(2): 800812.

32. Lau KS-Y and Crump MC (2015). HSV-1 gM and the gK/pUL20 Complex Are Important for the Localization of $\mathrm{gD}$ and $\mathrm{gH} / \mathrm{L}$ to Viral Assembly Sites. Viruses 7(3).

33. Herold BC, Visalli RJ, Susmarski N, Brandt CR, and Spear PG (1994). Glycoprotein C-independent binding of herpes simplex virus to cells requires cell surface heparan sulphate and glycoprotein B. J Gen Virol 75 ( Pt 6): 1211-1222.

34. Oh M-J, Akhtar J, Desai P, and Shukla D (2010). A role for heparan sulfate in viral surfing. Biochem Biophys Res Commun 391(1): 176181.

35. Spear $M$ and $W u Y$ (2014). Viral exploitation of actin: forcegeneration and scaffolding functions in viral infection. Virol Sin 29(3): 139-147.

36. Liu J and Pedersen LC (2007). Anticoagulant heparan sulfate: structural specificity and biosynthesis. Appl Microbiol Biotechnol 74(2): 263-272.

37. Shukla D, Liu J, Blaiklock P, Shworak NW, Bai X, Esko JD, Cohen GH, Eisenberg RJ, Rosenberg RD, and Spear PG (1999). A novel role for 3 O-sulfated heparan sulfate in herpes simplex virus 1 entry. Cell 99(1): 13-22.

38. Tiwari V, O'donnell C, Copeland RJ, Scarlett T, Liu J, and Shukla D (2007). Soluble 3-O-sulfated heparan sulfate can trigger herpes simplex virus type 1 entry into resistant Chinese hamster ovary (CHO-K1) cells. J Gen Virol 88(Pt 4): 1075-1079.

39. Nicola AV, Hou J, Major EO, and Straus SE (2005). Herpes simplex virus type 1 enters human epidermal keratinocytes, but not neurons, via a pH-dependent endocytic pathway. J Virol 79(12): 7609-7616.

40. Nicola AV, McEvoy AM, and Straus SE (2003). Roles for endocytosis and low $\mathrm{pH}$ in herpes simplex virus entry into HeLa and Chinese hamster ovary cells. J Virol 77(9): 5324-5332.

41. Cai WZ, Person S, Warner SC, Zhou JH, and DeLuca NA (1987). Linker-insertion nonsense and restriction-site deletion mutations of the gB glycoprotein gene of herpes simplex virus type 1. J Virol 61(3) 714-721..

42. Satoh T, Arii J, Suenaga T, Wang J, Kogure A, Uehori J, Arase N, Shiratori I, Tanaka S, Kawaguchi Y, Spear PG, Lanier LL, and Arase H (2008). PILRalpha is a herpes simplex virus-1 entry coreceptor that associates with glycoprotein B. Cell 132(6): 935-944. 
43. Arii J, Wang J, Morimoto $T$, Suenaga $T$, Akashi $H$, Arase $H$, and Kawaguchi $Y$ (2010). A single-amino-acid substitution in herpes simplex virus 1 envelope glycoprotein $B$ at a site required for binding to the paired immunoglobulin-like type 2 receptor alpha (PILRalpha) abrogates PILRalpha-dependent viral entry and reduces pathogenesis. J Virol 84(20): 10773-10783.

44. Wang J, Fan Q, Satoh T, Arii J, Lanier LL, Spear PG, Kawaguchi Y, and Arase $H$ (2009). Binding of herpes simplex virus glycoprotein $B$ (gB) to paired immunoglobulin-like type 2 receptor alpha depends on specific sialylated O-linked glycans on gB. J Virol 83(24): 13042-13045.

45. Suenaga $T$, Satoh $T$, Somboonthum $P$, Kawaguchi $Y$, Mori $Y$, and Arase H (2010). Myelin-associated glycoprotein mediates membrane fusion and entry of neurotropic herpesviruses. Proc Natl Acad Sci USA 107(2): 866-871.

46. Arii J, Goto $H$, Suenaga $T$, Oyama M, Kozuka-Hata $H$, Imai T, Minowa A, Akashi $H$, Arase $H$, Kawaoka $Y$, and Kawaguchi $Y(2010)$. Nonmuscle myosin IIA is a functional entry receptor for herpes simplex virus-1. Nature 467(7317): 859-862.

47 Handler CG, Eisenberg RJ, and Cohen GH (1996). Oligomeric structure of glycoproteins in herpes simplex virus type 1. J Virol 70(9): 6067-6070.

48. Handler CG, Cohen GH, and Eisenberg RJ (1996). Cross-linking of glycoprotein oligomers during herpes simplex virus type 1 entry. J Virol 70(9): 6076-6082.

49. Roop C, Hutchinson L, and Johnson DC (1993). A mutant herpes simplex virus type 1 unable to express glycoprotein $L$ cannot enter cells, and its particles lack glycoprotein H. J Virol 67(4): 2285-2297.

50. Hutchinson L, Browne H, Wargent V, Davis-Poynter N, Primorac S, Goldsmith K, Minson AC, and Johnson DC (1992). A novel herpes simplex virus glycoprotein, $\mathrm{gL}$, forms a complex with glycoprotein $\mathrm{H}(\mathrm{gH})$ and affects normal folding and surface expression of gH. J Virol 66(4): 2240-2250.

51. Browne $H$, Baxter $V$, and Minson $T$ (1993). Analysis of protective immune responses to the glycoprotein $\mathrm{H}$-glycoprotein $\mathrm{L}$ complex of herpes simplex virus type 1. J Gen Virol 74(12): 2813-2817.

52. Gianni T, Cerretani A, Dubois R, Salvioli S, Blystone SS, Rey F, and Campadelli-Fiume $G$ (2010). Herpes simplex virus glycoproteins $H / L$ bind to cells independently of \{alpha\}V\{beta\}3 integrin and inhibit virus entry, and their constitutive expression restricts infection. J Virol 84(8): 4013-4025

53. Cheshenko N, Trepanier JB, Gonzalez PA, Eugenin EA, Jacobs WRJ, and Herold BC (2014). Herpes simplex virus type 2 glycoprotein $H$ interacts with integrin alphavbeta3 to facilitate viral entry and calcium signaling in human genital tract epithelial cells. J Virol 88(17): 1002610038.

54. Gianni T, Salvioli S, Chesnokova LS, Hutt-Fletcher LM, and Campadelli-Fiume $G$ (2013). $\alpha v \beta 6$ - and $\alpha v \beta 8$-Integrins Serve As Interchangeable Receptors for HSV gH/gL to Promote Endocytosis and Activation of Membrane Fusion. PLoS Pathog 9(12): e1003806.

55. Gianni T, Massaro R, and Campadelli-Fiume G (2015). Dissociation of HSV gL from gH by alphavbeta6- or alphavbeta8-integrin promotes gH activation and virus entry. Proc Natl Acad Sci USA 112(29): E3901E3910.

56. Clement C, Tiwari V, Scanlan PM, Valyi-Nagy T, Yue BYJT, and Shukla D (2006). A novel role for phagocytosis-like uptake in herpes simplex virus entry. J Cell Biol 174(7): 1009-1021.

57. Akhtar J and Shukla D (2009). Viral entry mechanisms: cellular and viral mediators of herpes simplex virus entry. FEBS J 276(24): 72287236.
58. Tiwari V and Shukla D (2010). Phosphoinositide 3 kinase signalling may affect multiple steps during herpes simplex virus type-1 entry. J Gen Virol 91(Pt 12): 3002-3009.

59. Zheng $K$, Xiang $Y$, Wang $X$, Wang $Q$, Zhong $M$, Wang S, Wang $X$, Fan J, Kitazato K, and Wang Y (2014). Epidermal Growth Factor ReceptorPI3K Signaling Controls Cofilin Activity To Facilitate Herpes Simplex Virus 1 Entry into Neuronal Cells. mBio 5(1): e00958-13.

60. Cheshenko N, Trepanier JB, Stefanidou M, Buckley N, Gonzalez P, Jacobs W, and Herold BC (2013). HSV activates Akt to trigger calcium release and promote viral entry: novel candidate target for treatment and suppression. FASEB J Off Publ Fed Am Soc Exp Biol 27(7): 25842599 .

61. Dohner K, Wolfstein A, Prank U, Echeverri C, Dujardin D, Vallee R, and Sodeik $B$ (2002). Function of dynein and dynactin in herpes simplex virus capsid transport. Mol Biol Cell 13(8): 2795-2809.

62. Radtke K, Kieneke D, Wolfstein A, Michael K, Steffen W, Scholz T, Karger A, and Sodeik B (2010). Plus- and Minus-End Directed Microtubule Motors Bind Simultaneously to Herpes Simplex Virus Capsids Using Different Inner Tegument Structures. PLoS Pathog 6(7): e1000991.

63. Sodeik B, Ebersold MW, and Helenius A (1997). Microtubulemediated transport of incoming herpes simplex virus 1 capsids to the nucleus. J Cell Biol 136(5): 1007-1021.

64. Zhong $M$, Zheng $K$, Chen $M$, Xiang $Y$, Jin $F$, Ma K, Qiu X, Wang $Q$ Peng $T$, Kitazato $K$, and Wang $Y$ (2014). Heat-Shock Protein 90 Promotes Nuclear Transport of Herpes Simplex Virus 1 Capsid Protein by Interacting with Acetylated Tubulin. PLoS ONE 9(6): e99425.

65. He B, Gross M, and Roizman B (1997). The gamma(1)34.5 protein of herpes simplex virus 1 complexes with protein phosphatase 1alpha to dephosphorylate the alpha subunit of the eukaryotic translation initiation factor 2 and preclude the shutoff of protein synthesis by double-stranded RNA-activated protein kinase. Proc Natl Acad Sci USA 94(3): 843-848.

66. Talloczy Z, Virgin HW 4th, and Levine B (2006). PKR-dependent autophagic degradation of herpes simplex virus type 1. Autophagy 2(1): 24-29.

67. Orvedahl A, Alexander D, Talloczy Z, Sun Q, Wei Y, Zhang W, Burns D, Leib DA, and Levine B (2007). HSV-1 ICP34.5 confers neurovirulence by targeting the Beclin 1 autophagy protein. Cell Host Microbe 1(1) 23-35.

68. Yakoub AM and Shukla D (2015). Basal Autophagy Is Required for Herpes simplex Virus-2 Infection. Sci Rep 5: 12985.

69. Choi E-J and Kee S-H (2014). Axin expression delays herpes simplex virus-induced autophagy and enhances viral replication in L929 cells. Microbiol Immunol 58(2): 103-111.

70. Roizman B and Whitley RJ (2013). An inquiry into the molecular basis of HSV latency and reactivation. Annu Rev Microbiol 67: 355374.

71. Kramer MF, Chen SH, Knipe DM, and Coen DM (1998). Accumulation of viral transcripts and DNA during establishment of latency by herpes simplex virus. J Virol 72(2): 1177-1185.

72. Kramer MF and Coen DM (1995). Quantification of transcripts from the ICP4 and thymidine kinase genes in mouse ganglia latently infected with herpes simplex virus. J Virol 69(3): 1389-1399.

73. Kent JR, Kang W, Miller CG, and Fraser NW (2003). Herpes simplex virus latency-associated transcript gene function. J Neurovirol 9(3): 285-290.

74. Perng GC, Jones C, Ciacci-Zanella J, Stone M, Henderson G, Yukht A, Slanina SM, Hofman FM, Ghiasi $H$, Nesburn AB, and Wechsler SL (2000). Virus-induced neuronal apoptosis blocked by the herpes sim- 
plex virus latency-associated transcript. Science 287(5457): 15001503.

75. Bloom DC (2004). HSV LAT and neuronal survival. Int Rev Immunol 23(1-2): 187-198.

76. Shimeld C, Whiteland JL, Nicholls SM, Grinfeld E, Easty DL, Gao H, and Hill TJ (1995). Immune cell infiltration and persistence in the mouse trigeminal ganglion after infection of the cornea with herpes simplex virus type 1. J Neuroimmunol 61(1): 7-16.

77. Halford WP, Gebhardt BM, and Carr DJ (1996). Persistent cytokine expression in trigeminal ganglion latently infected with herpes simplex virus type 1. J Immunol 157(8): 3542-3549..

78. Liu T, Tang Q, and Hendricks RL (1996). Inflammatory infiltration of the trigeminal ganglion after herpes simplex virus type 1 corneal infection. J Virol 70(1): 264-271.

79. Chen SH, Garber DA, Schaffer PA, Knipe DM, and Coen DM (2000). Persistent elevated expression of cytokine transcripts in ganglia latently infected with herpes simplex virus in the absence of ganglionic replication or reactivation. Virology 278(1): 207-216.

80. Liu T, Khanna KM, Chen X, Fink DJ, and Hendricks RL (2000). CD8(+) $T$ cells can block herpes simplex virus type 1 (HSV-1) reactivation from latency in sensory neurons. J Exp Med 191(9): 1459-1466.

81. Wilcox CL and Johnson EM (1987). Nerve growth factor deprivation results in the reactivation of latent herpes simplex virus in vitro. J Virol 61(7): 2311-2315..

82. Hill JM, Garza HHJ, Helmy MF, Cook SD, Osborne PA, Johnson EMJ, Thompson HW, Green LC, O'Callaghan RJ, and Gebhardt BM (1997). Nerve growth factor antibody stimulates reactivation of ocular herpes simplex virus type 1 in latently infected rabbits. J Neurovirol 3(3): 206-211.

83. Kristie TM, Vogel JL, and Sears AE (1999). Nuclear localization of the C1 factor (host cell factor) in sensory neurons correlates with reactivation of herpes simplex virus from latency. Proc Natl Acad Sci USA 96(4): 1229-1233.

84. Dressler GR, Rock DL, and Fraser NW (1987). Latent herpes simplex virus type 1 DNA is not extensively methylated in vivo. J Gen Virol 68 ( Pt 6): 1761-1765.

85. Kubat NJ, Tran RK, McAnany P, and Bloom DC (2004). Specific histone tail modification and not DNA methylation is a determinant of herpes simplex virus type 1 latent gene expression. J Virol 78(3): 1139-1149.

86. Oh J and Fraser NW (2008). Temporal Association of the Herpes Simplex Virus Genome with Histone Proteins during a Lytic Infection. J Virol 82(7): 3530-3537.

87. Deshmane SL and Fraser NW (1989). During latency, herpes simplex virus type 1 DNA is associated with nucleosomes in a chromatin structure. J Virol 63(2): 943-947.

88. Kent JR, Zeng P-Y, Atanasiu D, Gardner J, Fraser NW, and Berger SL (2004). During lytic infection herpes simplex virus type 1 is associated with histones bearing modifications that correlate with active transcription. J Virol 78(18): 10178-10186.

89. Knipe DM and Cliffe A (2008). Chromatin control of herpes simplex virus lytic and latent infection. Nat Rev Micro 6(3): 211-221.

90. Kubat NJ, Amelio AL, Giordani NV, and Bloom DC (2004). The herpes simplex virus type 1 latency-associated transcript (LAT) enhanc$\mathrm{er} / \mathrm{rcr}$ is hyperacetylated during latency independently of LAT transcription. J Virol 78(22): 12508-12518.

91. Wang Q-Y, Zhou C, Johnson KE, Colgrove RC, Coen DM, and Knipe DM (2005). Herpesviral latency-associated transcript gene promotes assembly of heterochromatin on viral lytic-gene promoters in latent infection. Proc Natl Acad Sci USA 102(44): 16055-16059.

92. Amelio AL, McAnany PK, and Bloom DC (2006). A chromatin insulator-like element in the herpes simplex virus type 1 latency-associated transcript region binds CCCTC-binding factor and displays enhancerblocking and silencing activities. J Virol 80(5): 2358-2368.

93. Sun $\mathrm{L}$ and $\mathrm{Li} Q$ (2012). The miRNAs of herpes simplex virus (HSV). Virol Sin 27(6): 333-338.

94. Reynolds AE, Ryckman BJ, Baines JD, Zhou Y, Liang L, and Roller RJ (2001). $U(L) 31$ and $U(L) 34$ Proteins of Herpes Simplex Virus Type 1 Form a Complex That Accumulates at the Nuclear Rim and Is Required for Envelopment of Nucleocapsids. J Virol 75(18): 8803-8817.

95. Collins WJ and Johnson DC (2003). Herpes simplex virus gE/gI expressed in epithelial cells interferes with cell-to-cell spread. J Virol 77(4): 2686-2695..

96. Hadigal SR, Agelidis AM, Karasneh GA, Antoine TE, Yakoub AM, Ramani VC, Djalilian AR, Sanderson RD, and Shukla D (2015). Heparanase is a host enzyme required for herpes simplex virus-1 release from cells. Nat Commun 6: 6985.

97. van Leeuwen $H$, Elliott $G$, and $O^{\prime}$ Hare $P$ (2002). Evidence of a role for nonmuscle myosin II in herpes simplex virus type 1 egress. J Virol 76(7): 3471-3481.

98. Roberts KL and Baines JD (2010). Myosin Va enhances secretion of herpes simplex virus 1 virions and cell surface expression of viral glycoproteins. J Virol 84(19): 9889-9896.

99. Lafferty WE, Downey L, Celum C, and Wald A (2000). Herpes simplex virus type 1 as a cause of genital herpes: impact on surveillance and prevention. J Infect Dis 181(4): 1454-1457.

100. Mertz GJ, Rosenthal SL, and Stanberry LR (2003). Is herpes simplex virus type 1 (HSV-1) now more common than HSV-2 in first episodes of genital herpes? Sex Transm Dis 30(10): 801-802.

101. Lowhagen GB, Tunback P, Andersson K, Bergstrom T, and Johannisson $G$ (2000). First episodes of genital herpes in a Swedish STD population: a study of epidemiology and transmission by the use of herpes simplex virus (HSV) typing and specific serology. Sex Transm Infect 76(3): 179-182..

102. Bernstein DI, Lovett MA, and Bryson YJ (1984). Serologic analysis of first-episode nonprimary genital herpes simplex virus infection. Presence of type 2 antibody in acute serum samples. Am J Med 77(6): 1055-1060.

103. Corey $L$ and Spear PG (1986). Infections with herpes simplex viruses (1). N Engl J Med 314(11): 686-691.

104. Corey L, Adams HG, Brown ZA, and Holmes KK (1983). Genital herpes simplex virus infections: clinical manifestations, course, and complications. Ann Intern Med 98(6): 958-972.

105. Zhu J, Koelle DM, Cao J, Vazquez J, Huang ML, Hladik F, Wald A and Corey $L$ (2007). Virus-specific CD8+ T cells accumulate near sensory nerve endings in genital skin during subclinical HSV-2 reactivation. J Exp Med 204(3): 595-603.

106. Zhu J, Hladik F, Woodward A, Klock A, Peng T, Johnston C, Remington $M$, Magaret A, Koelle DM, Wald A, and Corey L (2009). Persistence of HIV-1 receptor-positive cells after HSV-2 reactivation is a potential mechanism for increased HIV-1 acquisition. Nat Med 15(8): 886-892.

107. Johnson KE, Redd AD, Quinn TC, Collinson-Streng AN, Cornish T, Kong X, Sharma R, Tobian AAR, Tsai B, Sherman ME, Kigozi G, Serwadda D, Wawer MJ, and Gray RH (2011). Effects of HIV-1 and herpes simplex virus type 2 infection on lymphocyte and dendritic cell density in adult foreskins from Rakai, Uganda. J Infect Dis 203(5): 602-609. 
108. Cunningham AL, Diefenbach RJ, Miranda-Saksena M, Bosnjak L, Kim M, Jones C, and Douglas MW (2006). The cycle of human herpes simplex virus infection: virus transport and immune control. J Infect Dis 194 Suppl 1: S11-S18.

109. Liu T, Khanna KM, Carriere BN, and Hendricks RL (2001). Gamma interferon can prevent herpes simplex virus type 1 reactivation from latency in sensory neurons. J Virol 75(22): 11178-11184.

110. Donaghy H, Bosnjak L, Harman AN, Marsden V, Tyring SK, Meng T-C, and Cunningham AL (2009). Role for plasmacytoid dendritic cells in the immune control of recurrent human herpes simplex virus infection. J Virol 83(4): 1952-1961.

111. Mott KR, Allen SJ, Zandian M, Konda B, Sharifi BG, Jones C, Wechsler SL, Town T, and Ghiasi H (2014). CD8 $\alpha$ Dendritic Cells Drive Establishment of HSV-1 Latency. PLoS ONE 9(4): e93444.

112. Mott KR, Allen SJ, Zandian M, and Ghiasi H (2014). Coregulatory interactions among CD8alpha dendritic cells, the latency-associated transcript, and programmed death 1 contribute to higher levels of herpes simplex virus 1 latency. J Virol 88(12): 6599-6610.

113. Koelle DM, Chen HB, Gavin MA, Wald A, Kwok WW, and Corey L (2001). CD8 CTL from genital herpes simplex lesions: recognition of viral tegument and immediate early proteins and lysis of infected cutaneous cells. J Immunol 166(6): 4049-4058.

114. Koelle DM, Frank JM, Johnson ML, and Kwok WW (1998). Recognition of herpes simplex virus type 2 tegument proteins by CD4 T cells infiltrating human genital herpes lesions. J Virol 72(9): 7476-7483.

115. Mackay IM, Harnett G, Jeoffreys N, Bastian I, Sriprakash KS, Siebert D, and Sloots TP (2006). Detection and discrimination of herpes simplex viruses, Haemophilus ducreyi, Treponema pallidum, and Calymmatobacterium (Klebsiella) granulomatis from genital ulcers. Clin Infect Dis Off Publ Infect Dis Soc Am 42(10): 1431-1438.

116. Corey L, Wald A, Celum CL, and Quinn TC (2004). The effects of herpes simplex virus-2 on HIV-1 acquisition and transmission: a review of two overlapping epidemics. J Acquir Immune Defic Syndr 35(5): 435-445.

117. Gupta R, Warren T, and Wald A (2007). Genital herpes. Lancet Lond Engl 370(9605): 2127-2137.

118. Ramaswamy M, McDonald C, Smith M, Thomas D, Maxwell S Tenant-Flowers $M$, and Geretti AM (2004). Diagnosis of genital herpes by real time PCR in routine clinical practice. Sex Transm Infect 80(5): 406-410.

119. Filen F, Strand A, Allard A, Blomberg J, and Herrmann B (2004). Duplex real-time polymerase chain reaction assay for detection and quantification of herpes simplex virus type 1 and herpes simplex virus type 2 in genital and cutaneous lesions. Sex Transm Dis 31(6): 331336

120. Lafferty WE, Krofft S, Remington M, Giddings R, Winter C, Cent A, and Corey $L$ (1987). Diagnosis of herpes simplex virus by direct immunofluorescence and viral isolation from samples of external genital lesions in a high-prevalence population. J Clin Microbiol 25(2): 323326.

121. LeGoff J, Pere $H$, and Belec $L$ (2014). Diagnosis of genital herpes simplex virus infection in the clinical laboratory. Virol J 11: 83.

122. Workowski K (2015). Sexually Transmitted Diseases Treatment Guidelines,

http://www.cdc.gov/mmwr/preview/mmwrhtml/rr6403a1.htm.

123. Wald A, Langenberg AGM, Krantz E, Douglas JMJ, Handsfield HH, DiCarlo RP, Adimora AA, Izu AE, Morrow RA, and Corey L (2005). The relationship between condom use and herpes simplex virus acquisition. Ann Intern Med 143(10): 707-713.
124. Keller MJ, Tuyama A, Carlucci MJ, and Herold BC (2005). Topical microbicides for the prevention of genital herpes infection. J Antimicrob Chemother 55(4): 420-423.

125. Yang D, Chertov O, and Oppenheim JJ (2001). Participation of mammalian defensins and cathelicidins in anti-microbial immunity: receptors and activities of human defensins and cathelicidin (LL-37). J Leukoc Biol 69(5): 691-697.

126. Lien S and Lowman HB (2003). Therapeutic peptides. Trends Biotechnol 21(12): 556-562.

127. Galdiero S, Falanga A, Tarallo R, Russo L, Galdiero E, Cantisani M, Morelli G, and Galdiero M (2013). Peptide inhibitors against herpes simplex virus infections. J Pept Sci Off Publ Eur Pept Soc 19(3): 148158.

128. Jose GG, Larsen IV, Gauger J, Carballo E, Stern R, Brummel R, and Brandt CR (2013). A Cationic Peptide, TAT-Cd(0), Inhibits Herpes Simplex Virus Type 1 Ocular Infection In Vivo. Invest Ophthalmol Vis Sci 54(2): 1070-1079.

129. Larsen IV and Brandt CR (2010). A Cationic TAT Peptide Inhibits Herpes Simplex Virus Type 1 Infection of Human Corneal Epithelial Cells. J Ocul Pharmacol Ther 26(6): 541-547.

130. Ali MM, Karasneh GA, Jarding MJ, Tiwari V, and Shukla D (2012). A 3-O-sulfated heparan sulfate binding peptide preferentially targets herpes simplex virus 2-infected cells. J Virol 86(12): 6434-6443.

131. Jaishankar D, Yakoub AM, Bogdanov A, Valyi-Nagy T, and Shukla D (2015). Characterization of a proteolytically stable D-peptide that suppresses herpes simplex virus 1 infection: implications for the development of entry-based antiviral therapy. J Virol 89(3): 1932-1938.

132. Levi M, Ruden U, Carlberg H, and Wahren B (1999). The use of peptides from glycoproteins G-2 and D-1 for detecting herpes simplex virus type 2 and type-common antibodies. J Clin Virol Off Publ Pan Am Soc Clin Virol 12(3): 243-252.

133. Antoine TE and Shukla D (2014). Inhibition of myosin light chain kinase can be targeted for the development of new therapies against herpes simplex virus type-1 infection. Antivir Ther 19(1): 15-29.

134 Antoine TE, Mishra YK, Trigilio J, Tiwari V, Adelung R, and Shukla D (2012). Prophylactic, therapeutic and neutralizing effects of zinc oxide tetrapod structures against herpes simplex virus type-2 infection. Antiviral Res 96(3): 363-375.

135. Ensign LM, Tang BC, Wang $Y-Y$, Tse TA, Hoen $T$, Cone $R$, and Hanes J (2012). Mucus-penetrating nanoparticles for vaginal drug delivery protect against herpes simplex virus. Sci Transl Med 4(138): 138 ra79.

136. Straus SE, Wald A, Kost RG, McKenzie R, Langenberg AG, Hohman P, Lekstrom J, Cox E, Nakamura M, Sekulovich R, Izu A, Dekker C, and Corey $L$ (1997). Immunotherapy of recurrent genital herpes with recombinant herpes simplex virus type 2 glycoproteins $D$ and $B$ : results of a placebo-controlled vaccine trial. J Infect Dis 176(5): 1129-1134.

137. Stanberry LR, Spruance SL, Cunningham AL, Bernstein DI, Mindel A, Sacks S, Tyring S, Aoki FY, Slaoui M, Denis M, Vandepapeliere $P$, and Dubin $G$ (2002). Glycoprotein-D-adjuvant vaccine to prevent genital herpes. N Engl J Med 347(21): 1652-1661.

138. Awasthi S, Mahairas GG, Shaw CE, Huang M-L, Koelle DM Posavad C, Corey L, and Friedman HM (2015). A Dual-Modality Herpes Simplex Virus 2 Vaccine for Preventing Genital Herpes by Using Glycoprotein C and D Subunit Antigens To Induce Potent Antibody Responses and Adenovirus Vectors Containing Capsid and Tegument Proteins as T Cell Immunogens. J Virol 89(16): 8497-8509.

139. Awasthi S, Huang J, Shaw C, and Friedman HM (2014). Blocking herpes simplex virus 2 glycoprotein E immune evasion as an approach 
to enhance efficacy of a trivalent subunit antigen vaccine for genital herpes. J Virol 88(15): 8421-8432.

140. Mo A, Musselli C, Chen H, Pappas J, Leclair K, Liu A, Chicz RM, Truneh A, Monks S, Levey DL, and Srivastava PK (2011). A heat shock protein based polyvalent vaccine targeting HSV-2: CD4(+) and CD8(+) cellular immunity and protective efficacy. Vaccine 29(47): 8530-8541.
141. Wald A, Koelle DM, Fife K, Warren T, Leclair K, Chicz RM, Monks S, Levey DL, Musselli C, and Srivastava PK (2011). Safety and immunogenicity of long HSV-2 peptides complexed with rhHsc70 in HSV-2 seropositive persons. Vaccine 29(47): 8520-8529. 